UCRL-JC-126513

PREPRINT

\title{
High-Power Laser Diodes at Various Wavelengths
}

\author{
M. A. Emanuel \\ J. A. Skidmore \\ R. J. Beach
}

This paper was prepared for submittal to the SPIE Photonics West '97 Symposium

San Jose, California

February 8-14, 1997

February 19, 1997

This is a preprint of a paper intended for publication in a journal or proceedings. Since changes may be made before publication, this preprint is made available with the understanding that it will not be cited or reproduced without the permission of the author. 


\section{DISCLAIMER}

This document was prepared as an account of work sponsored by an agency of the United States Government. Neither the United States Government nor the University of California nor any of their employees, makes any warranty, express or implied, or assumes any legal liability or responsibility for the accuracy, completeness, or usefulness of any information, apparatus, product, or process disclosed, or represents that its use would not infringe privately owned rights.

Reference herein to any specific commercial product, process, or service by trade name, trademark, manufacturer, or otherwise, does not necessarily constitute or imply its endorsement, recommendation, or favoring by the United States Government or the University of California. The views and opinions of authors expressed herein do not necessarily state or reflect those of the United States Government or the University of California, and shall not be used for advertising or product endorsement purposes. 


\title{
High-Power Laser Diodes at Various Wavelengths
}

\author{
M. A. Emanuel, J. A. Skidmore, R. J. Beach \\ Lawrence Livermore National Laboratory \\ 7000 East Avenue, Mail Stop L-441, Livermore, CA 94550
}

\begin{abstract}
High power laser diodes at various wavelengths are described. First, performance and reliability of an optimized large transverse mode diode structure at 808 and $941 \mathrm{~nm}$ are presented. Next, data are presented on a $9.5 \mathrm{~kW}$ peak power array at $900 \mathrm{~nm}$ having a narrow emission bandwidth suitable for pumping Yb:SFAP laser materials. Finally, results on a fiber-coupled laser diode array at $\sim 730 \mathrm{~nm}$ are presented.
\end{abstract}

Keywords: laser diode, InAlGaAs, AlGaAs, COD, Yb:S-FAP, Yb:YAG, PDT

\section{OPTIMIZED LARGE-MODE LASER DIODE STRUCTURE}

Reliability and catastrophic optical damage (COD) levels of laser diodes are determined in large part by the optical intensity at the facets. One approach to reducing the intensity at the facets is to design the diode transverse waveguide structure such that the mode width is large, thus effectively spreading the intensity over a larger area and reducing the facet loading. We have described such a structure, only partially optimized, previously ${ }^{1}$. A more fully-optimized version of this structure is given in Fig. 1. There the device is seen to

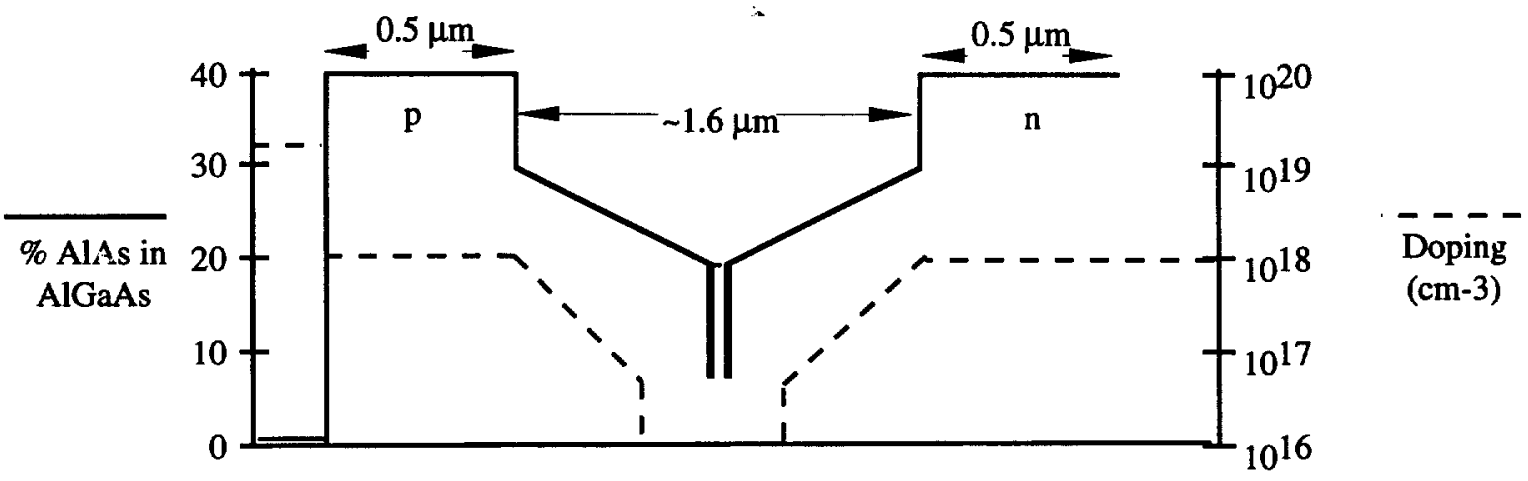

Figure 1. Optimized large-mode laser diode structure.

have characteristics of both conventional graded-index separate confinement (GRINSCH) and large optical cavity separate confinement heterostructure (LOC-SCH) structures. The band gap step between the cladding layers and the edges of the graded regions serves to improve carrier confinement, while the graded region both enhances carrier collection in the quantum wells and reduces the strength of the waveguide, compared to a standard LOC-SCH, so as to enlarge the optical mode. Doping concentrations are also given in Fig. 1, and the doping is seen to taper down as the active region is approached so as to minimize free carrier absorption losses, thus increasing differential quantum efficiency (DQE) and reducing the mode loss ${ }^{2}$. This device has been investigated at both 808 (In.10Al.15 Ga .75As wells) and $941\left(\mathrm{In}_{.14} \mathrm{Ga} .86 \mathrm{As}\right) \mathrm{nm}$, with the structure identical at both wavelengths except for the composition of the $70 \AA$ quantum wells. It was found that for both wavelengths that and active region comprising two quantum wells provided good performance for pulsed 
operation with pulse widths up to $400 \mu \mathrm{sec}$ and duty factors up to $25 \%$, but $\mathrm{cw}$ operation required three wells in order to avoid thermal rollover even at low power levels. Typical performance for uncoated, unmounted $100 \times 500 \mu \mathrm{m}$ devices having three quantum wells, under pulsed conditions of $10 \mathrm{~Hz}, 100 \mu \mathrm{sec}$ are $\mathrm{j}_{\mathrm{th}}=490 \mathrm{~A} / \mathrm{cm}^{2}$ and $\mathrm{DQE}=81 \%$ at $808 \mathrm{~nm}$, and $\mathrm{j}_{\mathrm{th}}=415 \mathrm{~A} / \mathrm{cm}^{2}$ and $\mathrm{DQE}=86 \%$ at $941 \mathrm{~nm}$.

In order to assess the reliability of these structures, $1 \mathrm{~cm} \times 1000 \mu \mathrm{m}$ bars, having $100 \mu \mathrm{m}$ emitters at a $71 \%$ fill factor were fabricated. The bars were coated and bonded to microchannel heatsinks ${ }^{3}$ for high average power evaluation. Reliability testing was done at a constant power of $100 \mathrm{~W}$ peak per bar using $400 \mu \mathrm{sec}$ pulses at $500 \mathrm{~Hz}$ (20\% duty factor) and $10^{\circ} \mathrm{C}$ coolant, and results for 808 and $941 \mathrm{~nm}$ bars are given in Fig. 2. There it is seen that while the $808 \mathrm{~nm}$ structure has a projected life (30\% degradation) of more than $10^{9}$ shots, the $941 \mathrm{~nm}$ device has a projected life of more than $10^{10}$ shots. Further reliability testing was done under cw conditions with $20^{\circ} \mathrm{C}$ coolant for the $941 \mathrm{~nm}$ structure and is shown in Fig. 3 for various power levels. Operation at 25 and $30 \mathrm{~W} / \mathrm{cm}$ yields projected lifetimes of greater than 10,000 hours (30\% degradation). Operation at $40 \mathrm{~W} / \mathrm{cm}$ yielded a lifetime of 1,700 hours, which is an encouraging result that is expected to improve as facet coatings are developed further.

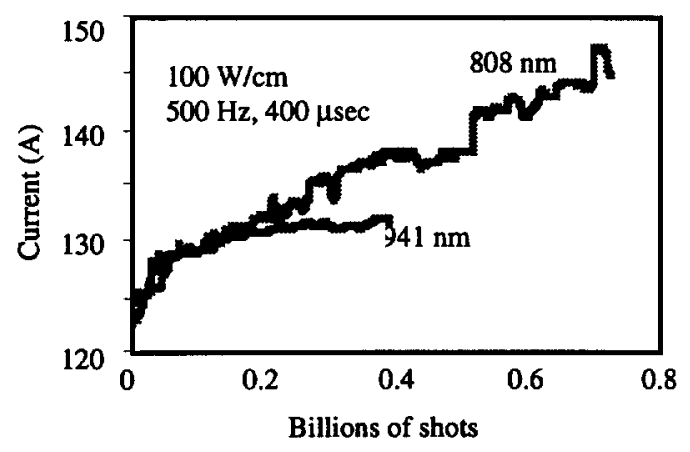

Figure 2. Pulsed reliability results.

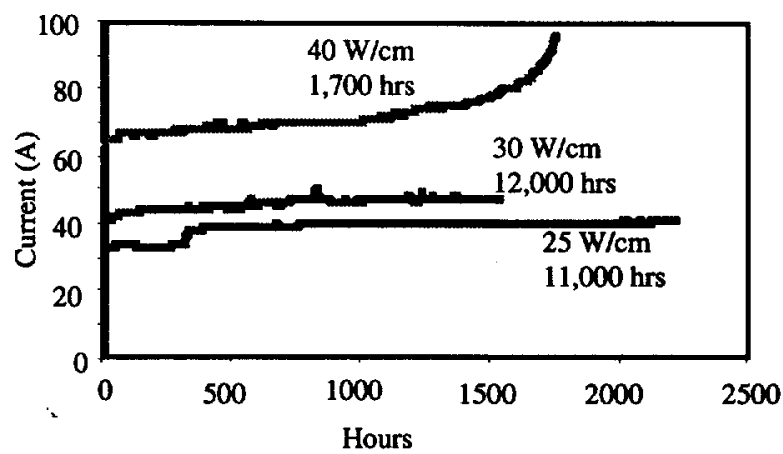

Figure 3. cw reliability results.

\section{HIGH-POWER ARRAY AT 900 NM}

Ytterbium-doped strontium fluoroapatite $\left(\mathrm{Sr}_{5}\left(\mathrm{PO}_{4}\right)_{3} \mathrm{~F}\right.$, or S-FAP) is a new laser material developed specifically for high-energy pulse applications. ${ }^{4}$ The appealing aspect of Yb:S-FAP is its fluorescence lifetime of approximately $1 \mathrm{~ms}$, which is approximately 5 times that of the commonly used Nd:YAG system. This 5-fold increase in storage time allows, for a given Q-switched pulse energy output, 5 times fewer diodes to be used in a Yb:S-FAP system than for a Nd:YAG system. That is, where 5 diodes might be required to pump a Nd:YAG laser for $200 \mu \mathrm{sec}$ before the desired energy is stored and then Q-switched out, a single diode could pump Yb:S-FAP for $1 \mathrm{~ms}$ to store the same amount of energy. Such a reduction in diode requirements is very attractive for high-energy pulsed laser systems, such as for laser fusion.

The pump wavelength for Yb:S-FAP is $900 \mathrm{~nm}$ with a FWHM of $\sim 3 \mathrm{~nm}$. The structure of the pump diodes used in this work is shown in Fig. 4. Performance of uncoated, unmounted devices under $10 \mathrm{~Hz}, 100 \mu \mathrm{sec}$ pulsed conditions yielded $\mathrm{j}_{\mathrm{th}}=192 \mathrm{~A} / \mathrm{cm}^{2}$ and a DQE of $85 \%$. Coated bars were fabricated $(15 \mathrm{~mm} \times 1 \mathrm{~mm}$ cavity, $100 \mu \mathrm{m}$ stripes, $71 \%$ fill) and mounted on microchannel coolers, and 96 of these packages were assembled into a pump array. Figure 5 shows that a peak power of approximately $9.5 \mathrm{~kW}$ was achieved at $41 \%$ power conversion efficiency under $20 \mathrm{~Hz}, 500 \mu \mathrm{sec}$ excitation with no evidence of thermal rollover. The emission spectrum of the array is given in Fig. 6 along with the absorption feature, and it is seen that good match is achieved. The $5.7 \mathrm{~nm}$ FWHM of the array is approximately broken down into $\sim 2.5 \mathrm{~nm}$ "natural" 
width, $\sim 1 \mathrm{~nm}$ of wafer growth variations and $\sim 2.7 \mathrm{~nm}$ of chirp during the pulse. Two such arrays were fabricated and used in a high-power Yb:S-FAP laser system. ${ }^{5}$

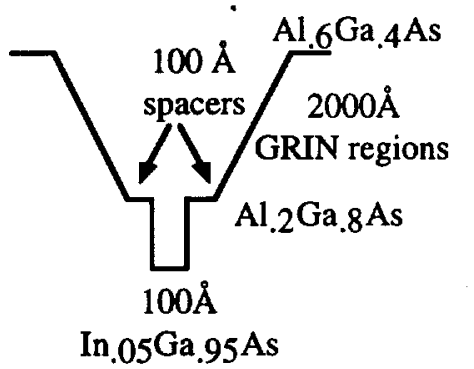

Figure 4. Structure of $900 \mathrm{~nm}$ diode.

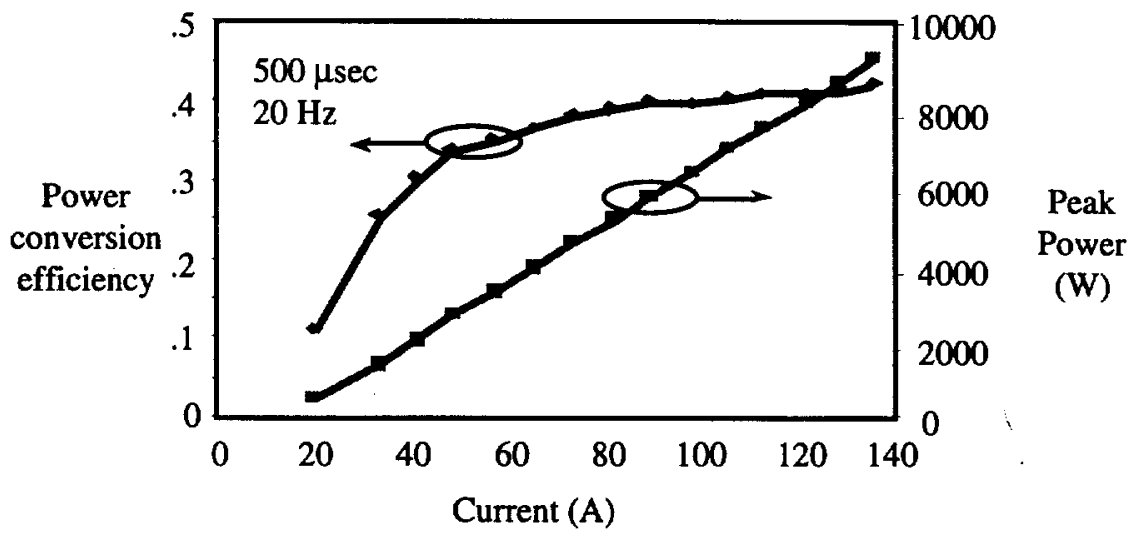

Figure 5. Performance of $900 \mathrm{~nm}$ diode array.

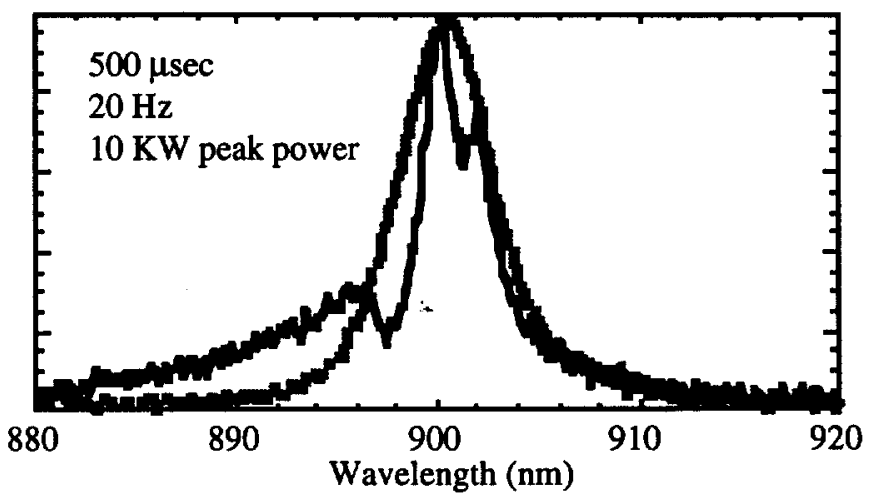

Figure 6. Diode array emission (gaussian) superimposed on the absorption line of Yb:S-FAP.

\section{FIBER-COUPLED ARRAY AT 731 NM}

In photodynamic therapy (PDT) treatment of cancer, a relatively non-toxic dye is injected into the body and selectively accumulates in cancerous tissue. When optically excited at the proper wavelength, the dye decomposes into toxic products, killing the cancerous tissue while leaving the surrounding tissue unharmed. Approximately $1 \mathrm{~W}$ of fiber-delivered $\mathrm{cw}$ power is required at the excitation wavelength. A promising dye for this treatment is lutecium texaphyrin which requires excitation at $\sim 731 \mathrm{~nm}$. Presently this wavelength is obtained with cumbersome and expensive argon ion-pumped Ti:sapphire lasers. A laser diode source would be welcome, but in the InAlGaAs/GaAs material system lasers at wavelengths below $\sim 750 \mathrm{~nm}$ tend to exhibit poor performance owing to the encroachment of indirect conduction band minima on the direct band gap.

A laser diode structure was developed for $731 \mathrm{~nm}$ operation and is shown in Fig. 7. It is a conventional GRINSCH having a single $60 \AA$ In.05Al.24Ga.71As quantum well. The $5 \%$ indium in the quantum well is intended to reduce the threshold current and inhibit the formation of dark-line defects. ${ }^{6}$ Evaluation of 
uncoated, unmounted $100 \times 500 \mu \mathrm{m}$ devices under $10 \mathrm{~Hz}, 100 \mu \mathrm{sec}$ excitation yielded $\mathrm{j}_{\mathrm{th}}=508 \mathrm{~A} / \mathrm{cm}^{2}$ and $\mathrm{DQE}=52 \%$. Coated bars were fabricated ( $5 \mathrm{~mm} \times 500 \mu \mathrm{m}, 100 \mu \mathrm{m}$ stripes, $71 \%$ fill $)$ and mounted on microchannel coolers and fitted with a collimating microlens. ${ }^{7}$ When operated at $7^{\circ} \mathrm{C}$ coolant temperature, these bars exhibited thermal rollover of the L-I characteristic between 5 and $10 \mathrm{~W} c \mathrm{cw}$ output. An array of 5 such bars was assembled at a $1 \mathrm{~mm}$ pitch, giving a $5 \times 5 \mathrm{~mm}$ emission aperture which was focused using a simple lens onto the end of a 0.37 NA fused silica $1 \mathrm{~mm}$ core fiber. In this manner ${ }^{8}$ a coupling efficiency of $\sim 50 \%$ was achieved, and $5 \mathrm{~W} \mathrm{cw}$ was delivered from the end of the fiber (power was not increased to the rollover point of the array output). An appealing feature of this fiber coupling technique is that the tip of the fiber may be quickly and easily replaced after use; this is an important feature for medical applications. Coupling schemes which are based on bundling "fiberlets" which are coupled to individual emitters do not easily lend themselves to simple replacement of the fiber tip. This fiber-coupled unit is being evaluated in medical trials.

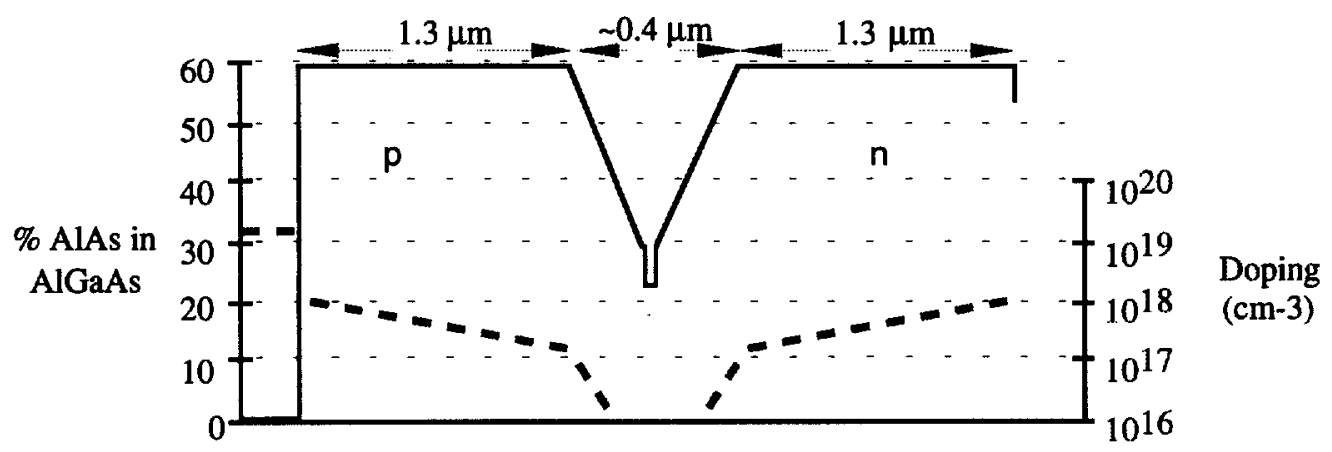

Figure 7. Structure of the $730 \mathrm{~nm}$ diode. The quantum well is $60 \AA$ In.05Al.24Ga.71As.

\section{ACKNOWLEDGMENTS}

The authors wish to thank L. DiMercurio, B. Freitas, C. Reinhardt, V. Sperry and E. Utterback for their expert technical contributiions, and S. A. Payne, H. T. Powell and W. F. Krupke for their encouragement and support. This work was performed under the auspices of the U. S. Department of Energy by Lawrence Livermore National Laboratory under contract W-7405-Eng-48.

\section{REFERENCES}

1. M. A. Emanuel, N. W. Carlson and J. A. Skidmore, "High-Efficiency AlGaAs-Based Laser Diode at 808 nm with Large Transverse Spot Size," IEEE Photon. Tech. Lett., vol. 8, pp.1291-1293, Oct. 1996.

2. R. G. Waters, D. S. Hill and S. L. Yellen, "Efficiency enhancement in quantum well lasers via tailored doping profiles," Appl. Phys. Lett., vol. 52, pp. 2017-2018, 1988.

3. R. J. Beach, W. J. Bennett, B. L. Freitas, D. Mundinger, B. J. Comaskey, R. W. Solarz and M. A. Emanuel, "Modular Microchannel Cooled Heatsinks for High Average Power Laser Diode Arrays," IEEE J. Quantum Electron., vol. 28, pp.966-976, 1992. 
4. C. D. Marshall, S. A. Payne, L. K. Smith, H. T. Powell, W. F. Krupke, and B. H. T. Chai, "1.047- $\mu \mathrm{m}$ $\mathrm{Yb}: \mathrm{Sr}_{5}\left(\mathrm{PO}_{4}\right)_{3} \mathrm{~F}$ Energy Storage Optical Amplifier, “ IEEE J. Selected Topics in Quantum Electron., vol. 1, pp. 67-77, 1995.

5. C. D. Marshall, L. K. Smith, R. J. Beach, M. A. Emanuel, K. I. Schaffers, J. A. Skidmore, S. A. Payne, and B. H. T. Chai, "Diode-Pumped Ytterbium-Doped $\mathrm{Yb}: \mathrm{Sr}_{5}\left(\mathrm{PO}_{4}\right)_{3} \mathrm{~F}$ Laser Performance," IEEE J. Quantum Electron., vol. 32, pp. 650-656, 1996.

6. S. L. Yellen, A. H. Shepard, R. J. Dalby, J. A. Baumann, H. B. Serreze, T. S. Guido, R. Soltz, K. J. Bystrom, C. M. Harding, and R. G. Waters, "Reliability of GaAs-Based Semiconductor Diode Lasers: $0.6-1.1 \mu \mathrm{m}$," IEEE J. Quantum Electron., vol. 29, pp. 2058-2067, 1993.

7. J. J. Snyder, P. Reichert and T. M. Baer, "Fast Diffraction-Limited Cylindrical Microlenses," Àppl. Opt., vol. 30, pp. 2743-2745, 1991.

8. R. J. Beach, M. A. Emanuel, B. L. Freitas, J. A. Skidmore, N. W. Carlson, W. J. Benett and R. W. Solarz, "Application of Microlens-Conditioned Laser Diode Arrays," SPIE, vol. 2383, pp. 283-297, 1995. 


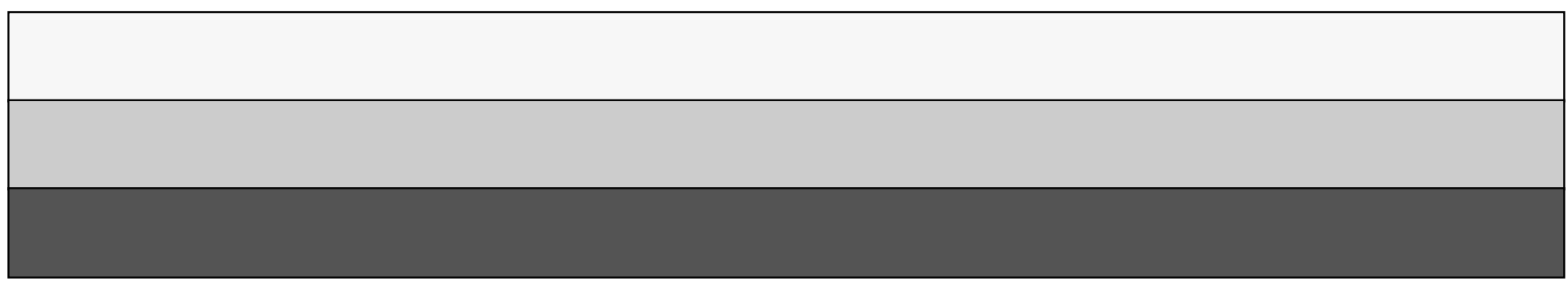

